\title{
EFFICIENCY OF NATURAL PRODUCT EMAMECTIN BENZOATE AGAINST COTTON LEAFWORM, SPODOPTERA LITTORALIS (BOISD) AND PINK BOLLWORM, PECTINOPHORA GOSSYPIELLA (SAUND.)
}

\author{
RASLAN, S.A.A., W.M.H. DESUKY, A.E.A. AMER AND A.A.A. EL-SAYED
}

Plant Protection Research institute, ARC, Dokki, Giza

(Manuscript received 3 May 2009)

\begin{abstract}
Field and laboratory trials were conducted in Zagazig - Sharkia Governorate during 2007 and 2008 cotton seasons to evaluate the efficacy of emamectin benzoate (against cotton leafworm Spodoptera littoralis and pink bollworm Pectinophora gossypiella. Emamectin benzoate resulted in initial kill of 93.73 and $92.39 \%$ reductions in the numbers of cotton leafworm Spodoptera littoralis, larvae, comparing with 98.22 and $95.93 \%$ for the recommended IGR hexaflumuron (Consult) (while as the residual effect emamectin benzoate revealed to 83.69 and $82.35 \%$ reductions comparing with 95.07 and $93.93 \%$ for the hexaflumuron, in 2007 and 2008 cotton seasons, respectively. The efficiency of emamectin benzoate in comparison with the recommended insecticide chlorpyriphos (Dursban) against cotton bollworm, pink bollworm, Pectinophora gossypiella, they resulted in 59.40 and $54.68 \%$ for emamectin benzoate, and 81.81 and $83.21 \%$ for chlorpyriphos as average seasonal reductions, during the two cotton seasons, respectively. Laboratory trials revealed that $L C 50$ and $L_{90}$ of emamectin benzoate were higher with cotton leafworm than pink bollworm, which were 2.783 and $1.656 \mathrm{ppm}$ at $\mathrm{LC}_{50}$, while they were 29.096 and $11.193 \mathrm{ppm}$ at $\mathrm{LC}_{90}$, respectively. The slope value of emamectin benzoate with cotton leafworm was 1.257 less than with pink bollworm which recorded 1.544 .
\end{abstract}

\section{INTRODUCTION}

Cotton leafworm, Spodoptera littoralis, and pink bollworm, Pectinophora gossypiella, are the major pest's destructive cotton fields in Egypt. The organophosphate, carbamate, and pyrethroide classes of insecticides represented the major elements for controlling these pests for many years. The environment, animals and human strongly affected by these hazard insecticides, as well as the insects became resistance in different degrees to their actions. So, it is necessary to use safe control agents including chemicals of new made of action in control programs of both insect pests.

Emamectin benzoate a new bioinsecticide was isolated from fermentation of Streptomyces avermitilis a naturally occurring soil. Biochemistry acts by stimulating the release of $\mathrm{y}$-aminobutyric acid, an inhibitory neurotransmitter thus causing paralysis, Tomlin (2003). 
Among the bioinsecticides, emamectin benzoate was found to be the best with the highest relative toxicity $(1093.2,986.5,870.6,254.3 \& 160.3$ times) than triazophos, cypermethrin, deltamethrin, chlorpyriphos and quinalphos, respectively, to resistant strain of Spodoptera litura (Fab.) to which the pest was developed high levels resistance Prasad et al. (2007). In field trial, abamectin $1.8 \%$ EC significantly effective in suppressing bollworm incidence of complex (Earias vittella, Helicoverpa armigera and Pectinophora gossypiella) and increased the seed cotton over control. They stated that the potentiality of abamectin would fit in very well towards the development of specific strategies and tactics for the management of bollworms complex with the novel molecules as an alternative to synthetic insecticides. Birah et al. (2008) and Raghuraman et al. (2008) suggested that the EC formulation of emamectin benzoate could be recommended as a component of sustainable management of bollworms in cotton.

This work aimed to evaluate the efficacy of emamectin benzoate against cotton leafworm, S. littoralis and pink bollworm, P. gossypiella, under field and laboratory conditions.

\section{MATERIALS AND METHODS}

Field and laboratory trials were carried to evaluate the efficacy of emamectin benzoate against major cotton insect pests on Egypt, cotton leafworm, $S$. littoralis and pink bollworm, P. gossypiella.

\section{FIELD TRIALS}

Field trials were carried out in Inshas Elbasal - Zagazig - Sharkia Governorate, during 2007 and 2008 cotton seasons.

\section{Cotton leafworm trials}

The emamectin benzoate (Emamectin EC 1.9\%) at the rate of $300 \mathrm{ml} / \mathrm{feddan}$, was evaluated against cotton leafworm, $S$. littoralis in cotton field in comparing with the recommended IGR hexaflumuron (Consult EC 10\%) at the rate of $200 \mathrm{ml} /$ feddan. Egg masses in three feddans of cotton field were not collected and left to hatching. When the hatched larvae reached to about the end of there $3^{\text {rd }}$ instar larvae, the area was divided into three equal areas of one feddan for each, representing the three treatments, emamectin benzoate, hexaflumuron and control. The numbers of cotton leafworm per 100 cotton plants (except the newly hatched larvae collected around the egg masses) were counted for every treatment before spray directly, then 400 liters of the insecticidal solutions were performed using earth motor. The numbers of cotton leafworm per 100 cotton plants were counted 5, 10 and 15 days after spray. Henderson and Telton (1955) equation was used to calculate the reduction 
percentages of cotton leafworm larvae. The reduction in numbers of larvae after 5 days was represented initial kill, and the average reduction after 10 and 15 days was represented residual effect.

\section{Pink bollworm trials}

The emamectin benzoate (EC 1.9\%) at the rate of $300 \mathrm{ml} /$ feddan, was evaluated against pink bollworm, Pectinophora gossypiella, in cotton field in comparing with the recommended insecticide chlorpyriphos (Dursban EC 48\%) at the rate of $1000 \mathrm{ml} /$ feddan

Area of one feddan of cotton field for every insecticide and control, was used to conduct the evaluation. Hundred green bolls were collected randomly from each treatment area and examined in laboratory. The numbers of pink bollworm larvae were recorded, and when the infestations reached to $5 \%$, the program of spray began. Three spray applications with 15 days interval of the two insecticides were done using 600 liters insecticidal solutions by earth motor. Hundred green bolls were collected randomly from each treatment before spraying and weekly after application, and reductions were calculated according to Henderson and Telton (1955) equation.

\section{LABORATORY TRIALS}

\section{1- Cotton leafworm}

A susceptible strain (laboratory strain) of $S$. littoralis was used in this experiment. Using a dipping technique, disks of castor bean leaves were dipped in graduated concentrations solutions of emamectin benzoate for 10 second, and left to dryness, and then offered to the $2^{\text {nd }}$ instar larvae in glass containers of $1 / 2 \mathrm{~kg}$ capacity, every glass container contain 10 larvae, and three replicates were used for every concentration and the same technique which used with control treatment using castor been leaves dipped in water only and dried before offered to the larvae. After treatment the larvae were held in electric incubator at $26 \pm 1{ }^{\circ} \mathrm{C}$ and $75 \pm 5 \% \mathrm{RH}$. After 24 hours the experiment was investigated and the dead larvae were recorded and removed. The alive larvae were transferred to another glass container contain untreated castor been leaves. The experiment was investigated daily till the $5^{\text {th }}$ day. The percent mortalities of larvae after 5 days were calculated and corrected when needed using abbott's formula (1925). The $\mathrm{LC}_{50}$ and $\mathrm{LC}_{90}$ were calculated according to Finny (1971)

\section{2- Pink bollworm}

The proper conditions and diet for maintaining laboratory colony of the pink bollworm, P. gossypiella were followed according to the method described by Abd ElHafez et al. (1982). 
Serial aqueous dilutions were prepared for emamectin benzoate. $1 \mathrm{ml}$. of each dilution was mixed with $5 \mathrm{~g}$ of artificial diet in Petri dishes and left to dryness. The newly hatched larvae of pink bollworm were offered to the Petri dishes. Four replicates of ten larvae were used for every dilution and another 4 replicates were left without treatment as check. After treatment, the larvae were held in electric incubator at $26 \pm 1$ ${ }^{\circ} \mathrm{C}$ and $75 \pm 5 \% \mathrm{RH}$. After 24 hours, the alive larvae were recorded and transferred to another clean Petri dishes contains untreated artificial diet. After 5 days, the percent mortalities were calculated and corrected according to Abbott's formula (1925). The LC50 and LC90 were calculated according to Finny (1971)

Results were analyzed by using a microcomputer based probit analysis. The concentration - mortality line for emamectin benzoate with every tested insect, and the $\mathrm{LC}_{50}$ and $\mathrm{LC}_{90}$ were determined.

\section{RESULTS AND DISCUSSION}

\section{FIELD TRIALS}

\section{Efficacy of emamectin benzoate against cotton leafworm Spodoptera littoralis}

The efficiency of emamectin benzoate comparing with the recommended insect growth regulator (IGR) hexaflumuron against cotton leafworm S. littoralis, during 2007 and 2008 cotton seasons was evaluated and the obtained data presented in Table (1).

For the initial kill which represent the percent reduction in the numbers of the cotton leafworm larvae after 5 days of insecticides application, emamectin benzoate resulted in 93.73 and $92.39 \%$ reductions comparing with 98.22 and $95.93 \%$ for the recommended IGR hexaflumuron, in 2007 and 2008 cotton seasons, respectively.

According to the residual effect as shown in Table (1), emamectin benzoate revealed 83.69 and $82.35 \%$ reductions comparing with 95.07 and $93.93 \%$ for the IGR, hexaflumuron, in 2007 and 2008 cotton seasons, respectively. Cook et al. (2007) found that emamectin benzoate controlled Spodoptera exigua infestation in cotton plant up to 10 days after treatment compared to the untreated. Argentine et al. (2002) reported that emamectin benzoate was effective in controlling Spodoptera exigua on sugar beet at projected field rate. Prasad et al. (2007) reported that emamectin was the most toxic against Spodoptera litura followed by novaluron and indoxacarb. Kumar et al. (2008) found that the $\mathrm{LC}_{50}$ value of emamectin benzoate was 0.00266 and 0.02 ug larva-1 for susceptible and field population of Earias vittella, respectively.

The previous data appeared highly efficiency of emamectin benzoate in controlling the larvae of cotton leafworm, and strongly showed a promise in using this 
compound in the integrated management of cotton leafworm, especially because it has a new mode of action than that of the recommended insecticides for this pest, and also for it's low toxicity against beneficial insects.

\section{Efficacy of emamectin benzoate against pink bollworm, Pectinophora gossypiella}

The efficiency of emamectin benzoate comparing with the recommended insecticide chlorpyriphos against cotton bollworm and pink bollworm, P. gossypiella, during 2007 and 2008 cotton seasons are presented in Table (2).

The two insecticides were applied three times with 15 days intervals on cotton plants to determine their efficiency in reducing the infestation of cotton green bolls with pink bollworm. The results revealed that chlorpyriphos was more active than emamectin benzoate. The average seasonal reductions rates were 59.40 and $54.68 \%$ for emamectin benzoate, and were recorded 81.81 and $83.21 \%$ for chlorpyriphos during 2007 and 2008 cotton seasons, respectively.

\section{LABORATORY TRIALS}

Data collected in Table (3) showed that at $\mathrm{LC}_{50}$ and $\mathrm{LC}_{90}$ values of emamectin benzoate were higher with cotton leafworm than pink bollworm, as they were 2.783 and $1.656 \mathrm{ppm}$ at $\mathrm{LC}_{50}$, while were 29.096 and $11.193 \mathrm{ppm}$ at $\mathrm{LC}_{90}$, respectively. The slope value of emamectin benzoate with cotton leafworm was 1.257 less than with pink bollworm which recorded 1.544 .

The obtained results shown in Table (3) clearly showed that emamectin benzoate was more toxic on pink bollworm, $P$. gossypiella, than cotton leafworm $S$. littoralis. Also, values of slope revealed that pink bollworm more susceptible for emamectin benzoate than cotton leafworm. Dhawan et al. (2007) found that the $\mathrm{LC}_{50}$ of emamectin benzoate against the third instar larvae of $S$. littoralis was $0.0001 \mathrm{ppm}$, and the emamectin benzoate was the most toxic insecticide comparing to other tested insecticides.

Concerning the toxic effects of emamectin benzoate against cotton leafworm and pink bollworm, data obtained from field and laboratory trials exhibited opposite effects against both insect pests. There for, so we must not depend on the results of laboratory as values can recorded in the field, because there is many factors in the field can change these values, such as photo stability Trans laminar uptake, leaf nutritional status, Verkerk and Wright (1996). Behavior feeding of the insect in the field, amount of toxicant uptake by the insect or the age of the insect, and many other factors.

Data obtained showed a promising to use emamectin benzoate in the integrated control programs of cotton leafworm, S. littoralis, and pink bollworm, P. gossypiella, 
1004 EFFICIENCY OF NATURAL PRODUCT EMAMECTIN BENZOATE AGAINST COTTON LEAFWORM, SPODOPTERA LITTORALIS (BOISD.) AND PINK BOLLWORM, PECTINOPHORA GOSSYPIELLA (SAUND.) 
1006 EFFICIENCY OF NATURAL PRODUCT EMAMECTIN BENZOATE AGAINST COTTON LEAFWORM, SPODOPTERA LITTORALIS (BOISD.) AND PINK BOLLWORM, PECTINOPHORA GOSSYPIELLA (SAUND.) 


\section{REFERENCES}

1. Abbott, W. S. 1925. A method of computing the effectiveness of an insecticide. J. Econ. Entomol., 18:265-267.

2. Abd El-Hafez, A. A., G. Metwally and M. R. A. Saleh. 1982. Rearing of the pink bollworm, Pectinophora gossypiella (Saund.) on kidney been diet (Lepidoptera: Gelechiidae). J. Econ. Entomol., 49:559-560.

3. Argentine, J. A., R. K. Jansson, W. R. Halliday, D. Rugg and C. S. Jany. 2002. Potency, spectrum and residual activity of four new insecticides under glasshouse conditions. Florida Entomologist, 85:552-562.

4. Birah A., M. Raghuraman, S. Brijesh and G. P. Gupta. 2008. Impact of abamectin complex in cotton. Indian Journal of Entomology, 70:259-263.

5. Cook, D. R., B. R. Leonard and J. Gore. 2007. Field and laboratory performance of novel insecticides against armywarms (Lepidoptera: Noctuidae). Florida Entomologist, 87:433-439.

6. Dhawan, A. K., S. Saini, B. Mohindru and K. Singh. 2007. Susceptibility of Spodoptera litura (Fabricius) to some novel insecticides. Pesticide Research Journal, 19:169-171.

7. Finny, J. D. 1971. Probit analysis (Third Edition). Cambridge University Press.UK.

8. Henderson, C. F. and E. W. Telton. 1955. Tests with acaricides against the brown wheat mite. J. Econ. Entomol. 48:157-161.

9. Kumar, M. S., S. V. Krishnamoorthy, S. Chandrasekaran and J. Stanlet. 2008. Baseline toxicity of emamectin benzoate and spinosad to Earias vittella in cotton. Annals of Plant Protection Sciences, 16(1):

10. Prasad K. D., T. Madhumathi, P. A. Rao and V. S. Rao. 2007. Toxicity of insecticides to resistant strain of Spodoptera litura (Fab.) on cotton. Annals of Plant Protection Science, 15:77-82.

11. Raghuraman M., B. Ajanta, S. Brijesh and G. P. Gupta. 2008. Bioefficacy of a newer insecticide emamectin benzoate $5 \%$ EC against cotton bollworms. Indian Journal of Entomology, 70:264-268.

12. Tomlin. 2003. The e-Pesticide Manual (Thirteenth Edition) Version 3.1.

13. Verkery, R. H. J. and D. J. Wright. 1996. Effects of interactions between host plants and selective insecticides on larval of Plutella xylostella L. (Lepidoptera:Yponomeutidae) in laboratory. Pesti. Sci., 46:171-181. 


\section{تقييم فعالية المركب الطبيعى ايمامكتين بنزوات علي كل من دودة ورق القطن ودودة اللوز القزنقلية}

سامي ابو الفتوح رسلان وحيد محمود حسين دسوقي عادل السيد على عامر ، علي احمد السيا

$$
\text { معهز بحوث وقاية النباتات - مركز البحوث الزراعية - الدقي - جيزة }
$$

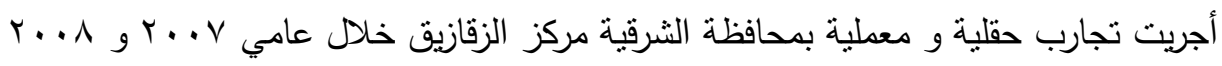

لتقييم تأثير مركب الأيمامكتين بنزوات علي دودة ورق القطم ودودة اللوز القرنفليه وقد أوضحت النتائج

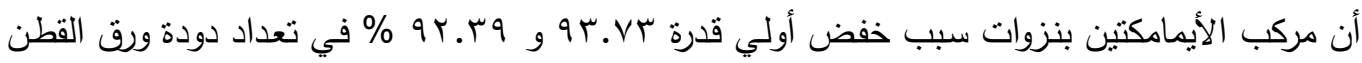

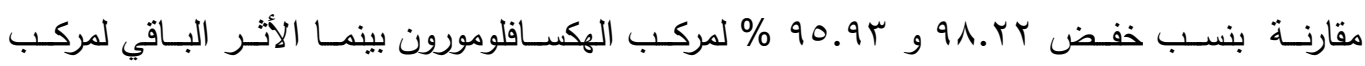





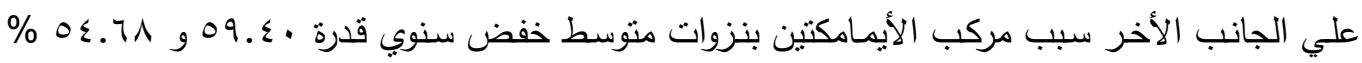

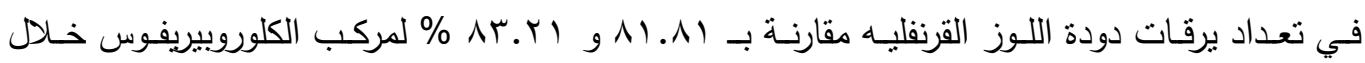





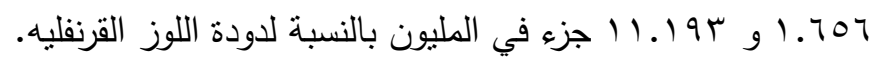

